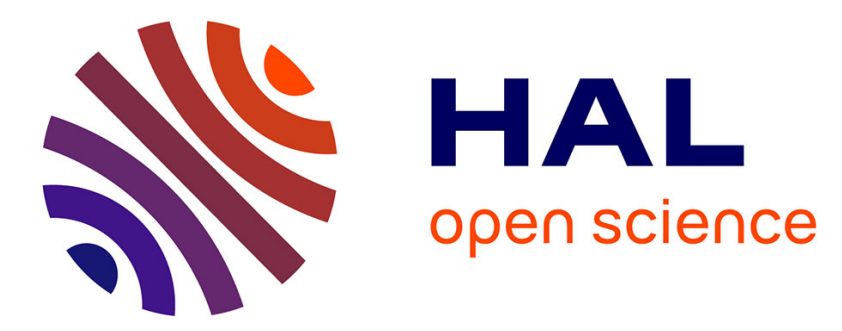

\title{
Direct Synthesis of Mesoporous Organosilica and Proof-of-Concept Applications in Lysozyme Adsorption and Supported Catalysis
}

Oriana Osta, Marianne Bombled, David Partouche, Florian Gallier, Nadège Lubin-Germain, Nancy Brodie-Linder, Christiane Alba-Simionesco

\section{To cite this version:}

Oriana Osta, Marianne Bombled, David Partouche, Florian Gallier, Nadège Lubin-Germain, et al.. Direct Synthesis of Mesoporous Organosilica and Proof-of-Concept Applications in Lysozyme Adsorption and Supported Catalysis. ACS Omega, 2020, 5, pp.18842 - 18848. 10.1021/acsomega.0c01996 . hal-03553249

\author{
HAL Id: hal-03553249 \\ https://hal.science/hal-03553249
}

Submitted on 2 Feb 2022

HAL is a multi-disciplinary open access archive for the deposit and dissemination of scientific research documents, whether they are published or not. The documents may come from teaching and research institutions in France or abroad, or from public or private research centers.
L'archive ouverte pluridisciplinaire HAL, est destinée au dépôt et à la diffusion de documents scientifiques de niveau recherche, publiés ou non, émanant des établissements d'enseignement et de recherche français ou étrangers, des laboratoires publics ou privés. 


\title{
Direct Synthesis of Mesoporous Organosilica and Proof-of-Concept Applications in Lysozyme Adsorption and Supported Catalysis
}

\author{
Oriana Osta,* Marianne Bombled, David Partouche, Florian Gallier, Nadège Lubin-Germain, \\ Nancy Brodie-Linder, and Christiane Alba-Simionesco
}

Cite This: https://dx.doi.org/10.1021/acsomega.0c01996

Q Read Online

ACCESS | ㅆll Metrics \& More | 回 Article Recommendations

ABSTRACT: Mesoporous materials represent a useful alternative for exploiting the effects of confinement on molecular trapping and catalysis. Their efficiency often depends on the interactions between the surface and the targeted molecules. One way to enhance these interactions is to adjust the hydrophobic/hydrophilic balance of the surface. In the case of mesoporous silica, the incorporation of organic groups is an efficient solution to adapt the material for specific applications. In this work, we have used the co-condensation method to control the hydrophobicity of mesoporous organosilica. The obtained materials are methyl- or phenyl-containing silica with a pore size between 3 and $5 \mathrm{~nm}$. The surface chemistry control has shown the enhanced performance of the materials in two proof-of-concept (PoC) applications: lysozyme adsorption and supported catalysis. The lysozyme adsorption is observed to be over 3 times more efficient with the phenyl-functionalized material than MCM-41, due to $\pi-\pi$ interactions.

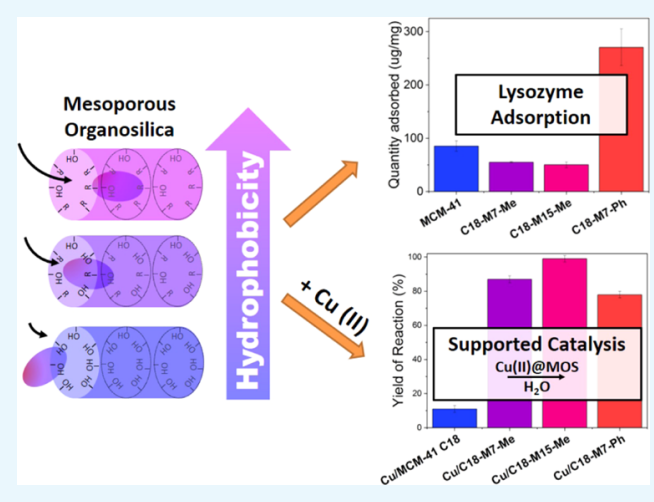
For the catalysis, copper(II) was immobilized on the organosilica surface. In this case, the presence of methyl groups significantly enhanced the product yield for the catalyzed synthesis of a triazole derivative; this was attributed to the enhanced hydrophobic surface-reactant interactions. It was also found that the materials have a higher water adsorption capacity and an improved resistance to hydrolysis. The modulation of water properties in confinement with hydrophobic surfaces, consistently with the water as tuneable solvent (WaTuSo) concept, is a crucial aspect in the efficiency of mesoporous materials for dedicated applications.

\section{INTRODUCTION}

Molecular trapping and supported catalysis are applications of mesoporous materials with great industrial and scientific impact. A key parameter for their efficiency is the hydrophobicity of the surface, accompanied by a large surface area and the appropriate pore size. ${ }^{1}$ Classic examples for applications in molecular trapping are the encapsulation followed by controlled drug delivery in nanomedicine, ${ }^{2}$ the effective removal of the low concentrations of pollutants, ${ }^{3}$ and molecular confinement studies, ${ }^{1,4-6}$ to mention a few. In the area of catalysis, mesoporous silica-supported reactions have been investigated, for example, in wastewater treatment, ${ }^{7}$ in reducing the amount of certain compounds in the mainstream of tobacco smoke, ${ }^{8}$ and in product yield improvement for organic reactions, ${ }^{9-11}$ among other applications. In a particular case, copper-doped nanoporous silica has been found to be a reusable, regioselective catalyst for the cycloaddition reaction between a terminal alkyne and an azide through click chemistry. ${ }^{10,12}$ However, in some cases, the yields of reaction are very low and this is attributed to the low interaction between the hydrophobic reactants and the hydrophilic materials.

In this context, MCM-41 offers high surface area, ordered structure, and thermal stability but fails in providing the correct hydrophobic/hydrophilic balance for efficient interaction with most organic molecules. Frequently, even after postgrafting hydrophobic groups on the surface, this balance is not met due to a total transformation of the surface from hydrophilic to hydrophobic. A partial functionalization with this method has shown to produce inhomogeneous, rough surfaces with the majority of the grafted groups on the external surface or at the extremes of the pores. $9,13,14$

The co-condensation method has been conceived as an alternative to introducing hydrophobic groups to mesoporous silica materials yielding a more uniform functionalization. ${ }^{9,15}$ In this case, a silica precursor is condensed together with an organosilane. This method has been studied to introduce acid, basic and unsaturated groups in the walls of MCM-41-like materials so that they can be directly used for catalytic applications. $^{14,16-18}$

Received: April 30, 2020

Accepted: July 13, 2020 
According to recent studies, the hydrophobicity of the nanoenvironment has an impact on the properties of confined water, which is the solvent used for both the applications studied. Indeed, under hydrophobic nanoconfinement, water undergoes changes in its $\mathrm{H}$-bond network, lowering its polarity and providing enhanced solvation of nonpolar solutes. This concept has been called water tuneable solvent (WaTuSo). ${ }^{19}$ Some consequences of this phenomenon have been, for example, enhanced gas storage ${ }^{2 \delta}$ and dramatic improvement of catalytic efficiency. ${ }^{21}$

In this context, our aim was to control the hydrophobicity of organosilica materials for specific applications by introducing methyl or phenyl groups through co-condensation with methyltriethoxysilane (MTES) or phenyltriethoxysilane (PTES), acting directly on water properties tuning its polarity for the specific applications.

Herein, we present a proof-of-concept (PoC) (i.e., evidence that demonstrates the suitability of these materials) for applications in protein adsorption and supported catalysis. Lysozyme was chosen as a model to study the effect of hydrophobicity in protein uptake. In addition, the supported copper (click) catalysis of the cycloaddition reaction between two hydrophobic reactants, benzyl azide and 4-bromo-1butyne, in aqueous media instead of an organic solvent, was tested with the synthesized materials.

During the direct synthesis of mesoporous organosilica, we focused on obtaining a stable material with a highly ordered pore structure. To avoid the disruption of the honeycomb-like structure and based on previous research, ${ }^{22,23}$ the percentage of organosilane in the precursor mixture was kept under 20 mol \%. The conditions of template washing by ethanol extraction were adjusted to obtain clean material without causing damages to the surface.

Samples were named according to the template used and their fraction of MTES or PTES in the precursor mixture: C18-M7-Me for 0.93 tetraethyl orthosilicate (TEOS)/0.07 MTES, C18-M15-Me for 0.85 TEOS/0.15 MTES, and C18M7-Ph for 0.93 TEOS/0.07 PTES, all of them using $\mathrm{C}_{18} \mathrm{TAB}$ as a template, and C12-M7-Me for 0.93 TEOS/0.07 MTES using $\mathrm{C}_{12} \mathrm{TAB}$ as a template. Standard MCM-41 C18 and C12 were synthesized and washed under the same conditions for comparison. Here, we mainly focus on the materials C18-M7$\mathrm{Ph}$ and C18-M15-Me materials, which showed an optimal performance in lysozyme trapping and as support for the click catalysis, respectively. A comprehensive characterization (Fourier transform infrared (FTIR), nitrogen and water adsorption, small-angle X-ray scattering (SAXS), transmission electron microscopy (TEM), INS) has been performed and is discussed herein; the details are provided in the Supporting Information.

\section{RESULTS AND DISCUSSION}

In Figure 1, the standard characterization of the materials is shown.

Template removal and incorporation of the organic groups in the mesoporous silica were verified by means of FTIR (Figure 1A). In all samples, the typical absorption bands at 1060, 796, and $445 \mathrm{~cm}^{-1}$ associated with $\mathrm{Si}-\mathrm{O}$ stretching and bending modes of condensed silica were found, as well as a band at $953 \mathrm{~cm}^{-1}$ associated with the $\mathrm{Si}-\mathrm{OH}$ groups at the surface. $^{24}$ In the spectra of samples C18-M7-Me and C18M15-Me, an absorption band at $1276 \mathrm{~cm}^{-1}$ is present; this band is attributed to the $\mathrm{C}-\mathrm{H}$ bending of the carbon bonded
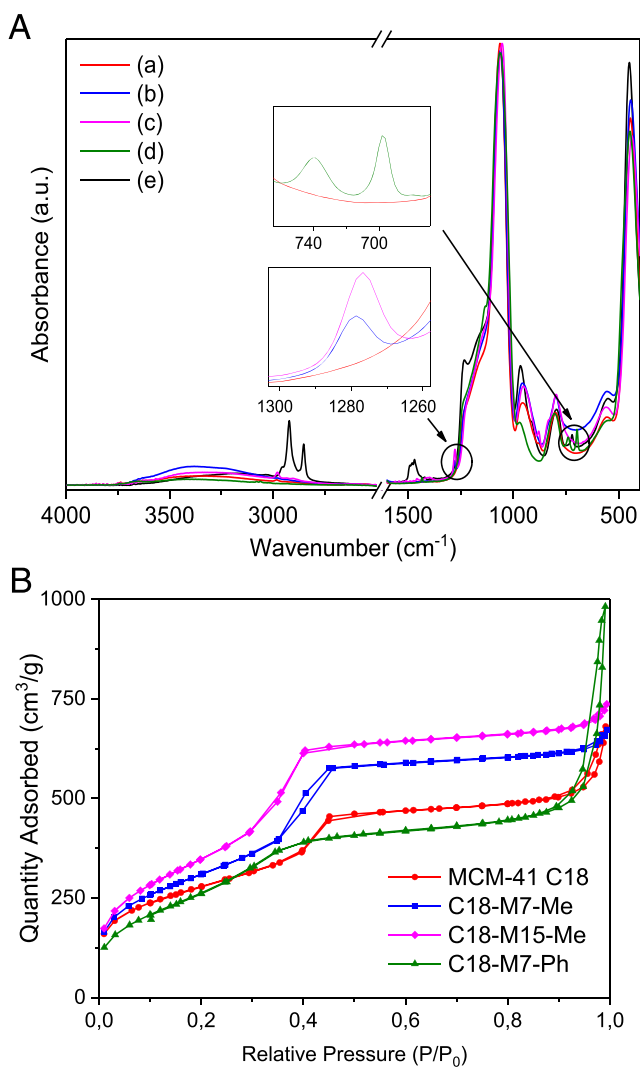

Figure 1. (A) FTIR spectra of (a) MCM-41 C18, (b) C18-M7-Me, (c) C18-M15-Me, (d) C18-M7-Ph, and (e) MCM-41, as synthesized. 1(B) Nitrogen adsorption-desorption isotherms of MCM-41 C18 and mesoporous organosilica materials at $77 \mathrm{~K}$.

to a $\mathrm{Si}$ atom, confirming the incorporation of the methyl group in the framework. The intensity of this band increases when the fraction of MTES used is larger. The incorporation of the phenyl group in sample $\mathrm{C} 18-\mathrm{M} 7-\mathrm{Ph}$ was identified by the peaks at $695-740 \mathrm{~cm}^{-1}$, from the aromatic $\mathrm{C}-\mathrm{H}$ bend. The absorption bands at 2921, 2852, and $1480 \mathrm{~cm}^{-1}$, from $\mathrm{C}-\mathrm{H}$ stretching and bending of the alkyl chain of $\mathrm{C}_{18} \mathrm{TAB}$, are only present in the as-synthesized material, indicating that the washing method has been efficient in removing the template.

Nitrogen adsorption and desorption isotherms of these samples at $77 \mathrm{~K}$ are shown in Figure 1B. For standard and methyl-modified MCM-41 C18, results show a regular type IV adsorption isotherm. In the case of co-condensation of TEOS with MTES, an increase in surface area and pore volume with respect to MCM-41 C18 was observed (see Table 1). On the other hand, the co-condensation with PTES produced a less organized material, evidenced by a spread capillary con-

Table 1. Mean Physical Properties of Selected Materials

\begin{tabular}{lccccc}
\multicolumn{1}{c}{ sample } & $\begin{array}{c}S_{\mathrm{BET}} \\
\left(\mathrm{m}^{2} / \mathrm{g}\right)\end{array}$ & $\begin{array}{c}V_{\text {pore }} \\
\left(\mathrm{cm}^{3} / \mathrm{g}\right)^{a}\end{array}$ & $\begin{array}{c}d_{10} \\
(\mathrm{~nm})^{b}\end{array}$ & $\begin{array}{c}D_{\text {pore }} \\
(\mathrm{nm})^{c}\end{array}$ & $C$ \\
$\begin{array}{l}\text { MCM-41 } \\
\text { C18 }\end{array}$ & 1007 & 0.712 & 4.45 & 4.22 & 112 \\
C18-M7-Me & 1130 & 0.899 & 4.48 & 4.43 & 77.7 \\
C18-M15-Me & 1284 & 0.982 & 4.31 & 4.32 & 57.2 \\
C18-M7-Ph & 989 & 0.628 & 4.65 & 4.30 & 44.1
\end{tabular}

${ }^{a}$ Single point adsorption total pore volume at $P / P_{0}=0.5$. ${ }^{b}$ Calculated from SAXS curves. ${ }^{c}$ Calculated using the $\mathrm{KJS}$ model taking into account the lattice plane spacing $\left(d_{10}\right){ }^{26}$ 
densation and slightly lower surface area and pore volume than those of MCM-41 C18.

The late condensation at $P / P_{0}$, higher than 0.9 in samples MCM-41 C18 and C18-M7-Ph, was attributed to condensation in the interparticle cavities when the size of the mesoporous silica grains are few tens of nanometers ${ }^{25}$ as evidenced for C18-M7-Ph by TEM (Figure S2).

It is worth noting that the affinity constant, $C$, calculated from the BET equation, decreased 49 and $61 \%$ with respect to the value of MCM-41 C18 ( C = 112) for C18-M15-Me and C18-M7-Ph, respectively. This parameter decreases with a decrease in the strength of the adsorbent-adsorbate affinity. Since induced dipole-dipole interactions govern this adsorption, the introduction of organic groups decreases the affinity of nitrogen toward the surface. Then, the observed drop in the $C$ value within the same family of materials is another evidence of their increasing hydrophobicity.

These results indicate that, upon the introduction of MTES at percentages up to $15 \%$, the obtained organosilica maintains an ordered pore structure while increasing their hydrophobic character; this was also confirmed by SAXS (Figure S1 in the Supporting Information).

By inelastic neutron scattering experiments (Figure S3), looking for the ability of the methyl groups to freely rotate, we are able to distinguish the populations of methyl groups trapped in the walls and those at the surface. The quantification of the two populations leads to an estimation of $30-35 \%$ of methyl groups trapped into the walls, while the rest $70-65 \%$ are at the surface. Besides the characterization aspect, this information about the distribution of methyl groups and the temperature range where the motions are active should help further investigation on the mobility of confined fluids.

Lysozyme Adsorption. The selected organosilica materials were placed in contact with a $0.5 \mathrm{mg} / \mathrm{mL}$ solution of lysozyme at $\mathrm{pH} 7.4$ at room temperature for $4 \mathrm{~h}$; then, they were filtered and the decrease in the concentration of the protein in a solution was measured by ultraviolet (UV) adsorption at $280 \mathrm{~nm}$. This allowed the calculation of the amount of lysozyme adsorbed per milligram of the molecular sieve. In the case of methyl-modified materials C18-M7-Me and C18-M15-Me, the quantities adsorbed per milligram of organosilica ( $55 \pm 1$ and $50 \pm 5 \mu \mathrm{g} / \mathrm{mg}$, respectively) were lower than those for the reference MCM-41 C18 (85 $\pm 10 \mu \mathrm{g}$ ) $\mathrm{mg}$ ). Remarkably, in the case of the phenyl-modified sample, C18-M7-Ph, a 3.2 times higher adsorption was observed (270 $\pm 30 \mu \mathrm{g} / \mathrm{mg}$ ).

Lysozyme adsorption is driven by electrostatic interactions between the $\mathrm{Si}-\mathrm{OH}$ groups and the positively charged protein at $\mathrm{pH}$ 7.4. Therefore, the presence of $-\mathrm{CH}_{3}$ instead of $-\mathrm{OH}$ groups on the surface could be one of the reasons for the lower quantity adsorbed by the methyl-modified silica. On the other hand, the high amount of lysozyme adsorbed by $\mathrm{C} 18-\mathrm{M} 7-\mathrm{Ph}$ is attributed to its ability to interact with the protein via electrostatic as well as $\pi-\pi$ interactions.

FTIR spectra (Figure 2) show peaks centered at 1656 and $1535 \mathrm{~cm}^{-1}$ corresponding to the amide I and amide II bands of lysozyme, respectively. The small peak at $1594 \mathrm{~cm}^{-1}$ comes from the aromatic $\mathrm{C}-\mathrm{C}$ stretching of the phenyl functionalization. The amide I band consists of $\mathrm{C}=\mathrm{O}$ stretching coupled with $\mathrm{N}-\mathrm{H}$ bending and $\mathrm{C}-\mathrm{H}$ stretching components. As these stretching modes are affected by the hydrogen bonds present in the different conformations ( $\alpha$-helix, parallel and antiparallel

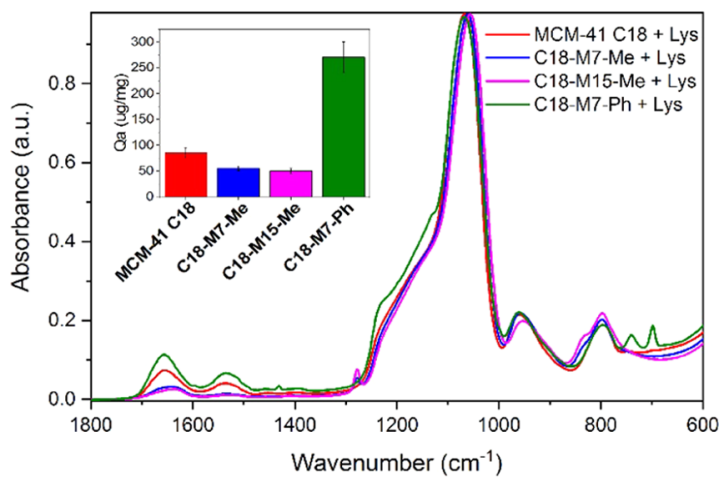

Figure 2. FTIR (ATR) spectra of the lysozyme adsorbed on the materials. Inset: quantities of lysozyme $(\mu \mathrm{g})$ adsorbed per milligram of material.

$\beta$-sheets, etc.), the shape of the amide I band gives information about the secondary structure of the protein. ${ }^{27}$ It is then possible to perform studies of protein structure under different confined conditions using these new molecular sieves.

Catalysis of the Alkyne-Azide Cycloaddition Reaction. The homogeneous azide-alkyne Huisgen cycloaddition reaction in solution is known to be very efficient, but it requires a copper(I) species as a catalyst. This species is prompt to disproportionate, making it necessary to add an auxiliary reducing species, as an ascorbate. Additionally, an extraction or filtration step has to be performed to purify the product. $^{28}$

The alternative here proposed is to use the synthesized nanoporous organosilica as support for copper(II) to perform the heterogeneous catalysis of this reaction.

This method has been used before for a variety of reactants, using mesoporous silica (SBA-15) as support. High conversion rates were obtained when the reactants were hydrophilic, but the yield of reaction decreased significantly for hydrophobic reactants; this was attributed to the hydrophilic character of the pores. ${ }^{12}$

The azide-alkyne cycloaddition reaction tested here between two hydrophobic reactants at ambient temperature, is shown in Figure 3.

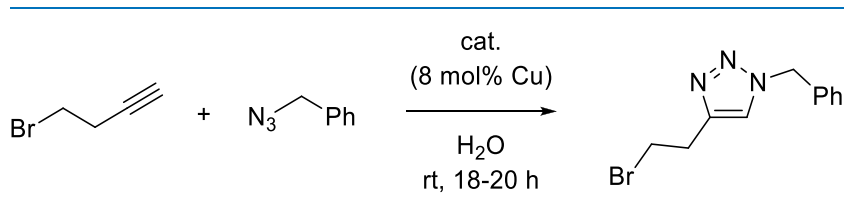

Figure 3. Cycloaddition reaction between bromobutyne and benzyl azide in the presence of a copper catalyst in water.

Copper(II) was immobilized on the materials using the method developed by Brodie-Linder et al. ${ }^{29}$ The materials were tested as catalysts for this reaction, with no addition of reducing agents or further ligands. It is worth noting that both reactants are not miscible in water. When the supported catalyst is added, the formation of a Pickering emulsion was observed for all of the reactions.

Figure 4 shows the yields of reaction obtained by means of NMR spectroscopy. A vast increase in the yield of the reaction is observed for the methyl- and phenyl-modified samples $\mathrm{Cu}$ / C18-M7-Me, Cu/C18-M15-Me, and Cu/C18-M7-Ph (87, $>99$, and $78 \%$ respectively) with respect to the yield of $11 \%$ obtained when $\mathrm{Cu} / \mathrm{MCM}-41 \mathrm{C} 18$ is used as a catalyst. The 


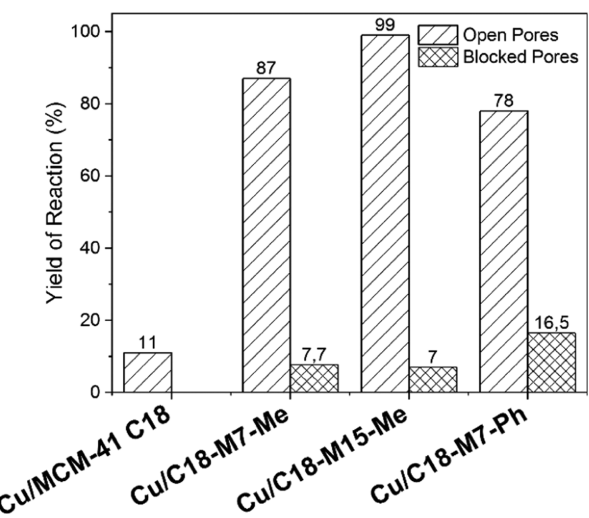

Figure 4. Yields of the cycloaddition reaction between bromobutyne and benzyl azide in water for different silica-supported copper catalysts with open and blocked pores.

formation of a Pickering emulsion was observed for all of the reactions.

These results confirm that the presence of methyl or phenyl groups enhances the adsorption of the organic reactants. The total transformation of the reactants on $\mathrm{Cu} / \mathrm{C} 18-\mathrm{M} 15-\mathrm{Me}$ indicates that this material provides an optimum nanoenvironment for this particular reaction in water.

Next, we checked if the catalysis takes place inside the nanopores by performing a control experiment, using copperdoped materials with pores blocked by surfactant. The procedure involved doping the as-synthesized nanoporous materials, i.e., without template removal by washing or calcination. The FTIR spectra of these materials are shown in Figure S4, where the peaks that correspond to the $\mathrm{C}-\mathrm{H}$ stretching and bending modes of the carbonated chain of the surfactant at 2921, 2852, and $1480 \mathrm{~cm}^{-1}$ can be observed.

Even though the molar percentage of copper in the reaction was maintained at $8 \mathrm{~mol} \%$, the yield of reaction obtained with blocked pores was much lower than the corresponding yield obtained with open pores (Figure 4), indicating that great part of the catalysis takes place inside the pores of the organosilica materials.

A photograph of an example of the catalytic mixture in the form of a Pickering emulsion and a schematic representation is shown in Figure S5. The copper-doped mesoporous particles acted not only as catalysts, providing nanopores with the proper hydrophobic/hydrophilic balance for the diffusion of reactants and products but also as an emulsifier. A higher local concentration, obtained by the Pickering emulsion process instead of simple dispersion in an organic solvent, could have enhanced the adsorption of the reactant molecules on the surface of the amphiphilic nanopores.

Furthermore, this method allows the substitution of organic solvents by water and the biphasic reaction system simplifies the recuperation of the catalyst by filtration. Such a reaction system could be extended to other sets of reactants, where one or both are water-immiscible, to take full advantage of the mass transport properties of Pickering emulsions. ${ }^{30,31}$

Role of Confined Water. We have seen so far, how, introducing a small percentage of methyl- or phenyltriethoxysilane in the reaction mixture can cause drastic effects in the performance of the mesoporous silica in key applications like molecular uptake and catalysis. We have attributed these results, mainly, to the adjustment of the surface chemistry.
Now, as both of the studied applications involve suspension of the material in water, we decided to investigate the behavior of the materials when they interact with water. We have investigated this by performing water vapor adsorption into the materials and a subsequent nitrogen adsorption experiment to evaluate the surface properties of the materials after interacting with water.

Water adsorption isotherms (Figure 5) show that the total quantity of water increases when the pore volume of the

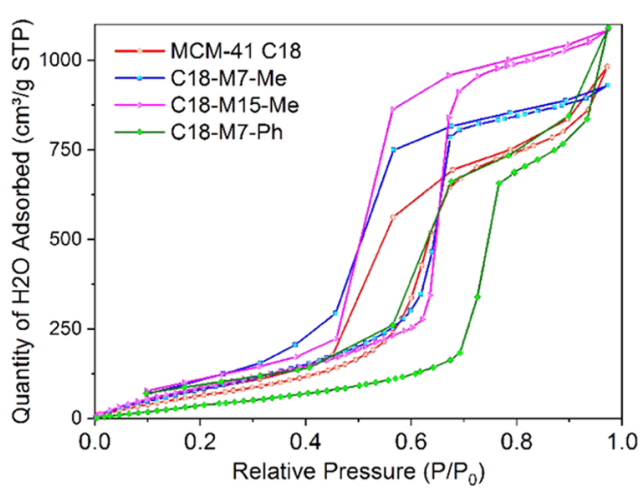

Figure 5. Water adsorption and desorption isotherms at $298.15 \mathrm{~K}$.

material is higher, regardless of their organic functionalization. These results show that the hydrophobicity of the materials is not strong enough to avoid water vapor condensation in the pores. It is well known that this is not the case for postgrafted hydrophobic organosilica, where the amount of water that can enter the pores, at atmospheric pressure, is negligible. The high water uptake found here seems to be a key parameter of the efficiency of the materials in the studied applications.

Recent studies show that, under hydrophobic nanoconfinement, water undergoes changes in its H-bond network, lowering its polarity and obtaining enhanced solvation of nonpolar solutes. This concept has been called Water Tuneable Solvent (WaTuSo). ${ }^{19}$ Some consequences of this phenomenon are, for example, enhanced gas storage ${ }^{20}$ and dramatic improvement of catalytic efficiency. ${ }^{21}$ Thus, it is arguable that the hydrophobic/hydrophilic materials used in this work have the ability not only to adsorb a large quantity of water but also to modulate the properties of water in confinement to match the polarity requirements for a dedicated application. The properties of water confined in these amphiphilic nanopores are currently under investigation and these will be treated in future publications.

Hydrothermal Resistance. It is known that mesoporous silica such as MCM-41 presents a low hydrothermal resistance, ${ }^{32-34}$ and this is one of the main disadvantages of this material for applications in aqueous media. For this reason, we have studied the surface degradation of the organosilica materials after contact with water.

During water adsorption experiments, the materials were in contact with water at neutral $\mathrm{pH}$ and $25{ }^{\circ} \mathrm{C}$. Afterward, they were heated to $90{ }^{\circ} \mathrm{C}$ under vacuum for $24 \mathrm{~h}$ to assure the elimination of any residual water molecule.

Even though soft conditions of $\mathrm{pH}$ and temperature were used, it was possible to compare the effects of this controlled exposure to water for the different materials.

Figure 6 shows nitrogen adsorption-desorption isotherms for the same organosilica samples before and after water adsorption (and desorption). The total quantity of $\mathrm{N}_{2}$ 


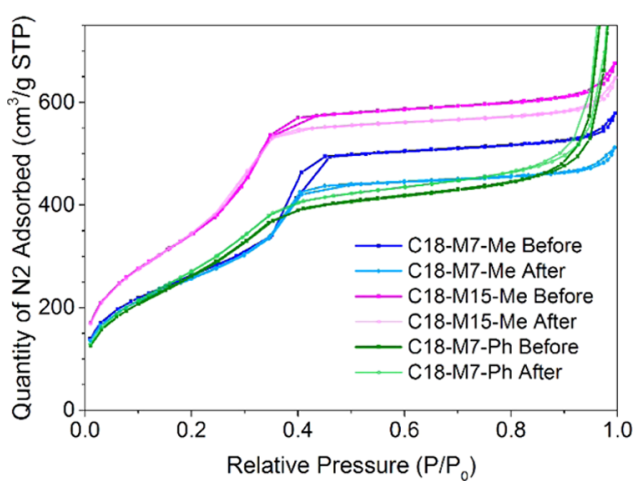

Figure 6. Nitrogen adsorption-desorption isotherms of selected materials at $77 \mathrm{~K}$ before and after water adsorption.

adsorbed after capillary condensation is directly related to the pore volume. This quantity decreases due to the pore structure degradation upon contact with water. In the case of C18-M7$\mathrm{Me}$, the quantity of $\mathrm{N}_{2}$ adsorbed at $P / P_{0}=0.5$ decreases by $11.8 \%$ of its initial value. A smaller difference $(4.22 \%)$ is observed in the case of $\mathrm{C} 18-\mathrm{M} 15-\mathrm{Me}$, while the pore volume of $\mathrm{C} 18-\mathrm{M} 7-\mathrm{Ph}$ is roughly constant (a small negative value of $3.16 \%$, attributable to the experimental error).

These results indicate that there is an increased stabilization of the surface toward hydrolysis when the hydrophobicity of the surface increases due to the presence of methyl or phenyl groups. Such resistance allows the material to be efficient in the time required for the local mechanism of the applications.

\section{CONCLUSIONS}

Using a direct synthesis of TEOS with MTES or PTES, mesoporous organosilica materials were produced for testing their applications in lysozyme adsorption and supported copper catalysis. A complete characterization confirmed the large surface area, ordered pore structure, and organic functionalization of the materials, providing a partial hydrophobic environment that depends on the percentage of organosilane present in the precursor mixture. It was observed that such a difference in the nanoenvironment had a significant impact on the performance of the materials in the selected applications.

The quantity of lysozyme adsorbed decreased for all of the methyl-modified materials, with respect to the original MCM41 C18. In contrast, the lysozyme uptake by the phenylmodified sample, C18-M7-Ph, was more than three times higher than that by the reference MCM-41. This enhancement is attributed to the $\pi-\pi$ interactions between the organosilica and the protein.

The copper-doped materials were proven to be active for regiospecific catalysis of the cycloaddition reaction between 4bromo-1-butyne and benzyl azide, using water as a solvent. In particular, C18-M15-Me provided an ideal surface for this reaction, with an obtained yield of the reaction of $>99 \%$.

Finally, we found that the high capacity for water uptake and modulations of its properties in hydrophobic nanoconfinement, together with better resistance to hydrolysis, were certainly important factors for the performance of C18-M7-Ph in lysozyme adsorption and for C18-M15-Me in the catalysis experiments.

\section{EXPERIMENTAL SECTION}

For the direct synthesis of mesoporous organosilica, we focused on obtaining a stable material with a highly ordered pore structure. To avoid the disruption of the honeycomb-like structure and based on previous research, ${ }^{22}$ the percentage of organosilane in the precursor mixture was kept under $20 \mathrm{~mol}$ $\%$.

Materials. Octadecyltrimethylammonium bromide $\left(\mathrm{C}_{21} \mathrm{H}_{6} \mathrm{NBr}\right)$, dodecyltrimethylammonium bromide $\left(\mathrm{C}_{15} \mathrm{H}_{6} \mathrm{NBr}\right)$, tetraethyl orthosilicate (TEOS), methyltriethoxysilane (MTES), phenyltriethoxysilane (PTES), ammonia (30\%), hydrochloric acid (37\%), and ethanol (99.98\%) were purchased from Sigma-Aldrich.

Direct Synthesis of Mesoporous Organosilica. MCM41-type materials with different percentages of MTES or PTES were prepared. For each one, $4 \mathrm{mmol}$ of the cationic surfactant $\mathrm{C}_{n} \mathrm{TAB}$ was dissolved in $72.0 \mathrm{~mL}$ of ultrapure water at $50{ }^{\circ} \mathrm{C}$ and stirred vigorously for $1.5 \mathrm{~h}$ for complete dissolution; then, the temperature was decreased to $35{ }^{\circ} \mathrm{C}$ and $4.8 \mathrm{~mL}$ of ammonia (30\%) was added. The mixture was stirred for further $5 \mathrm{~min}$. After, the precursors' mixture was added keeping the number of moles of the alkylethoxy and ethoxysilane (26.33 mmol) constant. The final molar composition of the reaction mixture was $(1-x)$ TEOS/ $x$ MTES (or PTES) $/ 2.4$ $\mathrm{NH}_{3} / 0.15 \mathrm{C}_{n} \mathrm{TAB} / 152 \mathrm{H}_{2} \mathrm{O}$, where $x$ is the fraction of methylor phenyltriethoxysilane that goes from 0 to 0.15 and $n$ is the length of the alkyl chain of the surfactant. The reaction was allowed to stir at a rate of $300 \mathrm{rpm}$ for $3.5 \mathrm{~h}$. The obtained white solid was washed twice with $40 \mathrm{~mL}$ of $\mathrm{HCl} 2 \% \mathrm{v} / \mathrm{v}$ and then with ultrapure water until reaching a neutral $\mathrm{pH}$.

The conditions of template removal were adjusted to obtain clean material without causing damages to the surface. For this purpose, two steps were needed: first, an acidification step, followed by an ethanol extraction step. The procedure was as follows: $100 \mathrm{~mL}$ of the aqueous solution of $\mathrm{HCl}(2 \% \mathrm{v} / \mathrm{v})$ was added per gram of the product and the mixture stirred for 25 min at room temperature. The solid was filtered and redispersed in a mixture of $200 \mathrm{~mL}$ of ethanol $99 \%$ and 10 $\mathrm{mL}$ of ultrapure water. This mixture was stirred at $50{ }^{\circ} \mathrm{C}$ for 3 $\mathrm{h}$; then, the solid was filtered and dried for $24 \mathrm{~h}$ in an oven at $60{ }^{\circ} \mathrm{C}$. The key parameters for a successful washing were the concentration and time of exposure to the acidic solution, as well as the presence of $5 \% \mathrm{v} / \mathrm{v}$ of water mixed with ethanol in the extraction step. The template extraction was verified by means of FTIR. An extra thermal treatment to accomplish total surfactant removal was only needed for the sample C18-M7$\mathrm{Ph}$. This sample was additionally heated at $350{ }^{\circ} \mathrm{C}$ for $1 \mathrm{~h}$ under a nitrogen atmosphere.

The samples were named according to the template used and their fraction of MTES or PTES in the precursor mixture: C18-M7-Me for 0.93 TEOS/0.07 MTES, C18-M15-Me for 0.85 TEOS/0.15 MTES, and C18-M7-Ph for 0.93 TEOS/0.07 PTES, all of them using $\mathrm{C}_{18} \mathrm{TAB}$ as a template, and C12-M7Me for 0.93 TEOS/0.07 MTES using $\mathrm{C}_{12} \mathrm{TAB}$ as a template. The standard MCM-41 C18 and C12 were synthesized and washed under the same conditions for comparison.

Characterization. The FTIR spectra of the samples were taken with a Bruker TENSOR equipped with a Platinum ATR from 4000 to $400 \mathrm{~cm}^{-1}$, with a resolution of $2 \mathrm{~cm}^{-1}$. Nitrogen and water vapor adsorption-desorption experiments were performed with an ASAP 2020 surface area and porosity analyzer from Micromeritics. Nanoporous silica samples were 
degassed under vacuum at $90{ }^{\circ} \mathrm{C}$ for $24 \mathrm{~h}$. Nitrogen adsorption isotherms were taken at $77 \mathrm{~K}$ and the water vapor adsorption isotherms at $298.15 \mathrm{~K}$. Thermogravimetric analyses were performed with a Q50 thermonuclear from TA Instruments under a controlled nitrogen gas flow from ambient temperature to $850{ }^{\circ} \mathrm{C}$ with a temperature ramp of $10^{\circ} \mathrm{C} / \mathrm{min}$. Small-angle $\mathrm{X}$-ray scattering patterns were collected using a Xeuss $2.0 \mathrm{HR}$ SAXS/WAXS instrument from Xenocs with a $\mathrm{Cu} \mathrm{K} \alpha(5 \mathrm{kV}$, 0.6 A). TEM images were taken with a JEOL JEM-2010 highresolution transmission electron microscope operating at 200 $\mathrm{kV}$.

Lysozyme Adsorption. Approximately $10 \mathrm{mg}$ of the selected materials was mixed with $10 \mathrm{~mL}$ of a $0.5 \mathrm{mg} / \mathrm{mL}$ solution of lysozyme from chicken egg white in a $10 \mathrm{mM}$

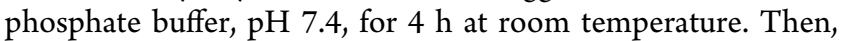
the suspensions were centrifuged for $10 \mathrm{~min}$ at $15000 \mathrm{~g}$, and 1 $\mathrm{mL}$ of the supernatant was passed through a $0.2 \mu \mathrm{m}$ filter and transferred to a quartz cell. The UV absorption spectra were taken at $280 \mathrm{~nm}$. The UV absorption spectra of the rinsing water were also taken to discard the loss of weakly bounded lysozyme. The solids were rinsed with water and dried under vacuum. The FTIR spectra of the lysozyme-rich materials were recorded.

Copper Postgrafting. The method of copper postgrafting followed the protocol described by Jlalia et al. ${ }^{12}$ One hundred and fifty milligrams of the washed nanoporous silica materials were added to $40 \mathrm{~mL}$ of a $0.05 \mathrm{M}$ solution of copper nitrate, previously adjusted to $\mathrm{pH} 10.5$ with ammonia (30\%) and stirred vigorously. Immediately after $10 \mathrm{~min}$, the solid was filtered and washed with ultrapure water until neutral $\mathrm{pH}$. The obtained blue material was dried in the oven at $50{ }^{\circ} \mathrm{C}$. The above-mentioned procedure was also applied to the assynthesized samples (without removing the surfactant from the pores) to obtain materials with copper grafted only on the external surface.

Catalytic Tests. For all samples, benzyl azide $(67 \mu \mathrm{L})$ and 4-bromo-1-butyne $(47 \mu \mathrm{L})$ were added to $2 \mathrm{~mL}$ of water containing a particular amount of copper-doped materials corresponding to $8 \mathrm{~mol} \%$ with respect to the benzyl azide reactant. Upon agitation, the mixture forms an $\mathrm{O} / \mathrm{W}$ Pickering emulsion. The reactions were performed for $20 \mathrm{~h}$. After that time, the mixtures were vacuum filtered with a polyacrylamide membrane and the blue solids were rinsed twice with $2 \mathrm{~mL}$ of ethyl acetate each time. After solvent evaporation, the conversion to 1-benzyl-4-bromoethyl-triazole was determined by ${ }^{1} \mathrm{H}$ NMR.

A control experiment was performed with the pores blocked by surfactant molecules $\left(\mathrm{C}_{18} \mathrm{TAB}\right)$ and copper grafted only on the external surface. The rest of the experimental conditions (time, temperature, concentration of reactants, $\mathrm{Cu} \mathrm{mol} \%$ in reaction mixture) were kept constant.

\section{ASSOCIATED CONTENT}

\section{SI Supporting Information}

The Supporting Information is available free of charge at https://pubs.acs.org/doi/10.1021/acsomega.0c01996.

Additional data on the characterization of the materials is available: mean physical properties of the additional prepared mesoporous organosilica materials, TEM images, small-angle X-ray scattering curves, neutron backscattering experiments, FTIR spectra of the copperdoped materials with the pores blocked with the surfactant, and photograph and schematic representations of the $\mathrm{O} / \mathrm{W}$ Pickering emulsion formed during catalysis experiments (PDF)

\section{AUTHOR INFORMATION}

Corresponding Author

Oriana Osta - Universite Paris-Saclay, CEA, CNRS, LLB, 91191 Gif-sur-Yvette, France; 이이.org/0000-0002-99096641; Email: oriana.osta@cea.fr

\section{Authors}

Marianne Bombled - Université Paris-Saclay, CEA, CNRS, LLB, 91191 Gif-sur-Yvette, France

David Partouche - Universite Paris-Saclay, CEA, CNRS, LLB, 91191 Gif-sur-Yvette, France; Universite Paris-Saclay, Synchrotron Soleil, 91190 Saint-Aubin, France

Florian Gallier - CY Cergy Paris Université, CNRS, BioCIS, 95000 Cergy-Pontoise, France; Universite Paris-Saclay, CNRS, BioCIS, 91190 Châtenay-Malabry, France

Nadège Lubin-Germain - CY Cergy Paris Universite, CNRS, BioCIS, 95000 Cergy-Pontoise, France; Universite Paris-Saclay, CNRS, BioCIS, 91190 Châtenay-Malabry, France; (1) orcid.org/0000-0003-0713-9286

Nancy Brodie-Linder - Université Paris-Saclay, CEA, CNRS, LLB, 91191 Gif-sur-Yvette, France; CY Cergy Paris Université, CNRS, BioCIS, 95000 Cergy-Pontoise, France; Universite ParisSaclay, CNRS, BioCIS, 91190 Châtenay-Malabry, France

Christiane Alba-Simionesco - Universite Paris-Saclay, CEA, CNRS, LLB, 91191 Gif-sur-Yvette, France

Complete contact information is available at:

https://pubs.acs.org/10.1021/acsomega.0c01996

\section{Notes}

The authors declare no competing financial interest.

\section{ACKNOWLEDGMENTS}

The authors thank Veronique Arluison for helpful discussion on the confined lysozyme, Annie Brûlet for the SAXS experiments, and Henriette Wase Hansen and Bernhard Frick for inelastic neutron scattering on IN16B at the ILL (Grenoble, France).

\section{REFERENCES}

(1) Lei, C.; Shin, Y.; Magnuson, J. K.; Fryxell, G.; Lasure, L. L.; Elliott, D. C.; Liu, J.; Ackerman, E. J. Characterization of Functionalized Nanoporous Supports for Protein Confinement. Nanotechnology 2006, 17, 5531-5538.

(2) Charnay, C.; Bégu, S.; Tourné-Péteilh, C.; Nicole, L.; Lerner, D. A.; Devoisselle, J. M. Inclusion of Ibuprofen in Mesoporous Templated Silica: Drug Loading and Release Property. Eur. J. Pharm. Biopharm. 2004, 57, 533-540.

(3) Cashin, V. B.; Eldridge, D. S.; Yu, A.; Zhao, D. Surface Functionalization and Manipulation of Mesoporous Silica Adsorbents for Improved Removal of Pollutants: A Review. Environ. Sci.: Water Res. Technol. 2018, 4, 110-128.

(4) Dosseh, G.; Xia, Y.; Alba-Simionesco, C. Cyclohexane and Benzene Confined in MCM-41 and SBA-15: Confinement Effects on Freezing and Melting. J. Phys. Chem. B 2003, 107, 6445-6453.

(5) Azaïs, T.; Laurent, G.; Panesar, K.; Nossov, A.; Guenneau, F.; Sanfeliu Cano, C.; Tourné-Péteilh, C.; Devoisselle, J.-M.; Babonneau, F. Implication of Water Molecules at the Silica-Ibuprofen Interface in Silica-Based Drug Delivery Systems Obtained through Incipient Wetness Impregnation. J. Phys. Chem. C 2017, 121, 26833-26839. 
(6) Brodrecht, M.; Kumari, B.; Breitzke, H.; Gutmann, T.; Buntkowsky, G. Chemically Modified Silica Materials as Model Systems for the Characterization of Water-Surface Interactions. Z. Phys. Chem. 2018, 232, 1127-1146.

(7) Wu, Q.; Hu, X.; Yue, P. L.; Zhao, X. S.; Lu, G. Q. Copper/ MCM-41 as Catalyst for the Wet Oxidation of Phenol. Appl. Catal., B 2001, 32, 151-156.

(8) Gomis, A. M.; Gómez Siurana, A.; Berenguer Muñoz, D.; Martínez Castellanos, I.; Beltrán, M. Effect of Mesoporous Catalysts on the Mainstream Tobacco Smoke of 3R4F and 1R5F Reference Cigarettes. Am. J. Chem. Eng. 2015, 3, 1-18.

(9) Mbaraka, I. K.; Shanks, B. H. Design of Multifunctionalized Mesoporous Silicas for Esterification of Fatty Acid. J. Catal. 2005, 229, 365-373.

(10) Roy, S.; Chatterjee, T.; Pramanik, M.; Roy, A. S.; Bhaumik, A.; Islam, Sk. M. Cu(II)-Anchored Functionalized Mesoporous SBA-15: An Efficient and Recyclable Catalyst for the One-Pot Click Reaction in Water. J. Mol. Catal. A: Chem. 2014, 386, 78-85.

(11) Rostamnia, S.; Doustkhah, E. Nanoporous Silica-Supported Organocatalyst: A Heterogeneous and Green Hybrid Catalyst for Organic Transformations. RSC Adv. 2014, 4, 28238-28248.

(12) Jlalia, I.; Gallier, F.; Brodie-Linder, N.; Uziel, J.; Augé, J.; LubinGermain, N. Copper(II) SBA-15: A Reusable Catalyst for AzideAlkyne Cycloaddition. J. Mol. Catal. A 2014, 393, 56-61.

(13) Wang, X.; Lin, K. S. K.; Chan, J. C. C.; Cheng, S. Direct Synthesis and Catalytic Applications of Ordered Large Pore Aminopropyl-Functionalized SBA-15 Mesoporous Materials. J. Phys. Chem. B 2005, 109, 1763-1769.

(14) Yokoi, T.; Yoshitake, H.; Tatsumi, T. Synthesis of AminoFunctionalized MCM-41 via Direct Co-Condensation and PostSynthesis Grafting Methods Using Mono-, Di- and Tri-AminoOrganoalkoxysilanes. J. Mater. Chem. 2004, 14, 951-957.

(15) Sayari, A.; Hamoudi, S. Periodic Mesoporous Silica-Based Organic-Inorganic Nanocomposite Materials. Chem. Mater. 2001, 13, 3151-3168.

(16) Shang, F.; Sun, J.; Wu, S.; Yang, Y.; Kan, Q.; Guan, J. Direct Synthesis of Acid-Base Bifunctional Mesoporous MCM-41 Silica and Its Catalytic Reactivity in Deacetalization-Knoevenagel Reactions. Microporous Mesoporous Mater. 2010, 134, 44-50.

(17) Macquarrie, D. J. Direct Preparation of Organically Modified MCM-Type Materials. Preparation and Characterisation of Aminopropyl-MCM and 2-Cyanoethyl-MCM. Chem. Commun. 1996, $1961-1962$.

(18) Fowler, C. E.; Burkett, S. L.; Mann, S. Synthesis and Characterization of Ordered Organo-Silica-Surfactant Mesophases with Functionalized MCM-41-Type Architecture. Chem. Commun. 1997, 1769-1770.

(19) Breynaert, E.; Houlleberghs, M.; Radhakrishnan, S.; Grübel, G.; Taulelle, F.; Martens, J. A. Water as a Tuneable Solvent: A Perspective. Chem. Soc. Rev. 2020, 49, 2557-2569.

(20) Casco, M. E.; Silvestre-Albero, J.; Ramírez-Cuesta, A. J. Methane hydrate formation in confined nanospace can surpass nature. Nat. Commun. 2015, 6, No. 6432.

(21) Liu, C.-C.; Chou, H.-J.; Lin, C.-Y.; Janmanchi, D.; Chung, P.W.; Mou, C.-Y.; Yu, S. S.-F.; Chan, S. I. The Oversolubility of Methane Gas in Nano-Confined Water in Nanoporous Silica Materials. Microporous Mesoporous Mater. 2020, 293, No. 109793.

(22) Burkett, S. L.; Sims, S. D.; Mann, S. Synthesis of Hybrid Inorganic-Organic Mesoporous Silica by Co-Condensation of Siloxane and Organosiloxane Precursors. Chem. Commun. 1996, $1367-1368$

(23) Putz, A.-M.; Wang, K.; Len, A.; Plocek, J.; Bezdicka, P.; Kopitsa, G. P.; Khamova, T. V.; Ianăşi, C.; Săcărescu, L.; Mitróová, Z. Mesoporous Silica Obtained with Methyltriethoxysilane as CoPrecursor in Alkaline Medium. Appl. Surf. Sci. 2017, 424, 275-281.

(24) Llusar, M.; Monrós, G.; Roux, C.; Pozzo, J. L.; Sanchez, C. One-Pot Synthesis of Phenyl- and Amine-Functionalized Silica Fibers through the Use of Anthracenic and Phenazinic Organogelators. J. Mater. Chem. 2003, 13, 2505-2514.
(25) Marei, N. N.; Nassar, N. N.; Vitale, G. The Effect of the Nanosize on Surface Properties of $\mathrm{NiO}$ Nanoparticles for the Adsorption of Quinolin-65. Phys. Chem. Chem. Phys. 2016, 18, 6839-6849.

(26) Kruk, M.; Jaroniec, M.; Sayari, A. Adsorption Study of Surface and Structural Properties of MCM-41 Materials of Different Pore Sizes. J. Phys. Chem. B 1997, 101, 583-589.

(27) Adams, S.; Higgins, A. M.; Jones, R. A. L. Surface-Mediated Folding and Misfolding of Proteins at Lipid/Water Interfaces. Langmuir 2002, 18, 4854-4861.

(28) Himo, F.; Lovell, T.; Hilgraf, R.; Rostovtsev, V. V.; Noodleman, L.; Sharpless, K. B.; Fokin, V. V. Copper(I)-Catalyzed Synthesis of Azoles. DFT Study Predicts Unprecedented Reactivity and Intermediates. J. Am. Chem. Soc. 2005, 127, 210-216.

(29) Brodie-Linder, N.; Besse, R.; Audonnet, F.; LeCaer, S.; Deschamps, J.; Impéror-Clerc, M.; Alba-Simionesco, C. The Key to Control $\mathrm{Cu}$ II Loading in Silica Based Mesoporous Materials. Microporous Mesoporous Mater. 2010, 132, 518-525.

(30) Zhao, Y.; Zhang, X.; Sanjeevi, J.; Yang, Q. Hydroformylation of 1-Octene in Pickering Emulsion Constructed by Amphiphilic Mesoporous Silica Nanoparticles. J. Catal. 2016, 334, 52-59.

(31) Zhang, M.; Ettelaie, R.; Yan, T.; Zhang, S.; Cheng, F.; Binks, B. P.; Yang, H. Ionic Liquid Droplet Microreactor for Catalysis Reactions Not at Equilibrium. J. Am. Chem. Soc. 2017, 139, 1738717396.

(32) Pérez, L. L.; van Eck, E. R. H.; Melián-Cabrera, I. On the Hydrothermal Stability of MCM-41. Evidence of Capillary TensionInduced Effects. Microporous Mesoporous Mater. 2016, 220, 88-98.

(33) Jiang, C.; Su, A.; Li, X.; Zhou, T.; He, D. Study on the Hydrothermal Stability of MCM-41 via Secondary Restructure. Powder Technol. 2012, 221, 371-374.

(34) Prouzet, E.; Kacheff, A.; Aubert, G.; Bentaleb, A.; Backov, R.; Aymonier, C. Toward a Sustainable Preparation of Tunable Mesoporous Silica. J. Supercrit. Fluids 2019, 143, 139-145. 